First Peoples Child \& Family Review

An Interdisciplinary Journal Honouring the Voices, Perspectives, and Knowledges of
First Peoples through Research, Critical Analyses, Stories, Standpoints and Media

Reviews

\title{
The Frontline of Revitationalization: Influences Impacting Aboriginal Helpers
}

\section{Suzy Goodleaf and Wanda Gabriel}

Volume 4, Number 2, 2009

URI: https://id.erudit.org/iderudit/1069327ar

DOI: https://doi.org/10.7202/1069327ar

See table of contents

Publisher(s)

First Nations Child and Family Caring Society of Canada

ISSN

1708-489X (print)

2293-6610 (digital)

Explore this journal

Cite this article

Goodleaf, S. \& Gabriel, W. (2009). The Frontline of Revitationalization:

Influences Impacting Aboriginal Helpers. First Peoples Child \& Family Review,

4(2), 18-29. https://doi.org/10.7202/1069327ar

\section{Article abstract}

Over the past two decades Aboriginal people have been transforming family, community and national life. With a fierce determination a movement that motivates change to heal destructive colonial and abusive patterns that has been simmering. On the front line of this movement are our elders, healers, counselors, social workers, police, teachers and faith keepers. The challenges facing the front line workers are very personal and at times political. This article seeks to shed light on the challenges of those on the front line of revitalization. It is based on the authors' experiences and observations of Aboriginals professionals and para-professionals (helpers) who are employed in their home communities, and highlights the specific influences they often face on a daily basis.
This document is protected by copyright law. Use of the services of Érudit (including reproduction) is subject to its terms and conditions, which can be viewed online.

https://apropos.erudit.org/en/users/policy-on-use/ 


\title{
INitest Peoples Child \& Samily Review
}

An Interdisciplinary Journal Honoring the Voices, Perspectives and Knowledges of First Peoples through Research, Critical Analyses, Stories, Standpoints and Media Reviews

\section{The Frontline of Revitalization: Influences Impacting Aboriginal Helpers}

\author{
Suzy Goodleafa and Wanda Gabriel ${ }^{b}$
}

\begin{abstract}
a M.Ed., Masters in Counseling Psychology, McGill University, Post Graduate degree in Marriage and Family Counseling; Present employment: Private practice in Kahnawake, Quebec, Canada.

${ }^{\mathrm{b}}$ MSW, McGill University, Certificate in Addictions Counseling, Unversitié de Sherbrooke; Present employment: Cree Relations Services Societié d'Energié Baie James, Canada.
\end{abstract}

\begin{abstract}
O Great Spirit whose voice I hear in the winds, I come to you as one of your many children. I need your strength and your wisdom. Make me strong not to be superior to my brother, but to be able to fight my greatest enemy: "Myself."
\end{abstract}

Chief Dan George

\section{Introduction}

Within the past two decades Aboriginal people have been transforming family, community and nation life. Many have undertaken this quest with a fierce motivation to change destructive colonial and abusive patterns. This simmering healing movement has created revitalization in Aboriginal identity and culture. On the front line of this movement are our elders, healers, faith keepers, teachers, counselors, community workers, police, Aboriginal professionals and paraprofessionals; they are the forerunners of revitalization in our communities.

On a daily basis, these helpers face the dilemma of working in a community in which they have personal investment through family and friends, making it often excruciatingly difficult to separate personal life and Questions or correspondence concerning this article may be
addressed to:

wandagabriel@sympatico.ca

\begin{abstract}
Over the past two decades Aboriginal people have been transforming family, community and nation life. With a fierce determination a movement that motivates change to heal destructive colonial and abusive patterns has been simmering. On the front line of this movement are our elders, healers, counsellors, social workers, police, teachers and faith keepers. The challenges facing the front line workers are very personal and at times political. This article seeks to shed light on the challenges of those on the front line of revitalisation. It is based on the authors" experiences and observations of Aboriginals professionals and para-professionals (helpers) who are employed in their home communities, and highlights the specific influences they often face on a daily basis.
\end{abstract}

professional life. The helpers/workers confront ethical challenges that burden their souls. A child welfare worker, the only worker in the community, is awakened in the middle of the night by a knock on the door, only to find her nieces and nephews, fearful and teary eyed, who have come for help because Dad is beating up their mom. Not only does the worker have to provide safety for her relatives, she must also intervene in this situation. There is no one else she can pass the case to. The same emotional bind occurs as the lone police officer is called in to deal with a suicide of a family member; despite his grief, he must process the death on an administrative level.

This article focuses on the authors' experiences and observations regarding challenges faced by Aboriginal front line workers. These challenges are very personal and at times political. The impacts of colonization and oppression are omnipresent throughout our relationships and our societal systems such as education, health and social, governance, economy including justice. Our frontline workers who are called in to deal with traumas due to the legacy are really at the forefront of decolonizing. However this privileged position comes with a level of stress that often goes unacknowledged. 
In this article we will address some of the impacts that are causing our frontline workers to be stressed. We will draw upon theories by structural social worker Robert Mullaly in how people survive oppression. We will address the, "magical thinking," in relation to our work and how we can get trapped into being the "caped crusader." Additionally we will address the issue of lateral violence, an analysis first coined by Jane Middleton-Moz a clinical psychologist that has been one of the leaders in the Aboriginal healing process. Lateral violence is destroying the social and spiritual fabric of our kinships.

Throughout the past seven years, we have had the privileges of working with Aboriginal frontline workers through our "Care for Caregivers" workshops. This has provided us with an opportunity to identify a plethora of influences that challenge the balance of our well being as frontline workers. These include issues pertaining to historical trauma, cultural, communal and personal expectations, "knowing" when knowing too much becomes a burden, and the juggling of loyalty to our families and duty to our chosen professions.

Support mechanisms in place for Aboriginal workers are often inadequate, making it far more difficult for our workers to balance community/personal/ professional lives. For Aboriginal workers, personal and professional investment is quite intertwined. Aboriginal service organizations fall short in addressing the role conflict and overlapping relationships of personal and professional boundaries that many Aboriginal workers face. The human cost on the Aboriginal professionals and paraprofessionals' personal and private lives is immeasurable. Consequently, Aboriginal workers remain at high risk for vicarious trauma and burnout. Vicarious trauma and burnout are an inevitable aspect of the helping profession, which does not receive the attention required to nurture our front line. When a human being is confronted on a daily basis with the darkest parts of our reality such as suicide, homicide, family violence, it is only natural that a burn on the soul occurs.

This article seeks to shed light on some of the challenges faced by our front line force, in the hopes of providing suggestions through the sharing of best practices for maintaining balance.
The authors write this article informed primarily by their own practice in Aboriginal community healing, presenting a cumulative experience spanning several decades. They are further informed by close to 200 Aboriginal service providers who have participated and shared in their yearly workshops "Care for Caregivers."

Within this article, the authors will identify some of the ethical dilemmas and the stressors/influences that impact workers positively and negatively, as well as provide an explanation as to how and why Aboriginal workers can get caught in the burnout trap. From their own wellness plans, they share practices that help them maintain balance in their personal and professional lives.

This article will hopefully serve several purposes; to give voice to the frontline reality, to honour the extraordinary service providers in Aboriginal communities, and finally to encourage policy makers and community planners to build compassionate support systems for the front line of revitalization.

\section{The Influences}

What we have learned through our own experiences and through the shared experiences of workers who attended our workshops is that there are influences and stressors that shape and form our professional identity that come to affect the efficiency and efficacy of our interventions. These determining factors affect the way in which we work. Though each frontline worker has their own individual tendencies, characteristics and gifts, it is clear that how we share these in our work is very much influenced by our personal and community history, ethics, and values. The influences we will discuss cover items such as historical trauma, culture, community and personal expectations, knowing when knowing too much becomes a burden, the juggling of loyalty and duty to profession and family. The double-edged sword of caring that can lead a worker to vicarious trauma and burnout.

Being visual learners we have put together some visuals that help us in understanding our perspective. In this article readers will find a diagram that divides these influences into a circular perspective.

\section{Acknowledgements:}

The healing and revitalization of our culture could not take place without the dedication and commitment of Aboriginal social workers, addiction counsellors, teachers, community health representatives, Elders, police officers, prevention workers, nurses, human resource managers, coordinators, etc. Thank you for your courage, thank you for being there with our people in times of suicide, homicide, gang violence, death and other traumas. Thank you for bearing witness to our strength and resiliency. Thank you to Diane Labelle and Pamela Gabriel-Ferland for helping us put our combined experiences and words together in a good way. 


\section{The Frontline of Revitalization: Influences Impacting Aboriginal Helpers}

\section{Historical Trauma}

Our personal history, our family history, our community history and our nation history has a major influence on our role as helpers and workers. To know where we come from is critical to our personal identity as well as our professional identity. To conduct oneself with confidence requires a solid understanding of self, a connection to culture and language, a sense of belonging, and a belief in something greater than self; the connection to spirituality.

In recent years researchers have begun to examine the role of historical trauma as a major influence in development of Aboriginal nations. Wesley-Esquimaux \& Smolewski (2004) state that:

$$
\begin{aligned}
& \text { A new model of historic trauma transmission } \\
& \text { (HTT) is proposed to create a better understanding } \\
& \text { of the etiology of social and cultural diffusion } \\
& \text { that disrupted Aboriginal communities for so } \\
& \text { many years. In this model, historic trauma is } \\
& \text { understood as a cluster of traumatic events and } \\
& \text { as a disease itself. Hidden collective memories of } \\
& \text { this trauma, or a collective non-remembering, is } \\
& \text { passed from generation to generation, as are the } \\
& \text { maladaptive social and behavioural patterns that } \\
& \text { are symptoms of many social disorders caused } \\
& \text { by historic trauma. There is no "single" historic } \\
& \text { trauma response; rather, there are different social } \\
& \text { disorders with respective clusters of symptoms. } \\
& \text { HTT disrupts adaptive social and cultural patterns } \\
& \text { and transforms them into maladaptive ones, which } \\
& \text { manifest themselves into symptoms of social } \\
& \text { disorder. In short, historic trauma causes deep } \\
& \text { breakdowns in social functioning that may last for } \\
& \text { many years, decades and even generations (p.iv). }
\end{aligned}
$$

As stated there is a cluster of symptoms that manifest in our community and as workers we have a responsibility to know who we are, how historical trauma is manifesting and how our culture is surviving.

\section{Culture}

Children were encouraged to develop strict discipline and a high regard for sharing. When a girl picked her first berries and dug her first roots, they were given away to an elder so she would share her future success (Morning Dove Salish, 2009).

A significant influence in our role as front line workers/helpers is the value of culture. Many of the people who participated in our workshops shared various views on culture. As well, many people have different levels of understanding of what culture means in a contemporary world. Many agree that in order for our people to survive and for revitalization to flourish culture must be a part of our work. A value/expectation of Aboriginal culture is to share, to be of service. There is a high level of importance placed on giving back to the community through service and our ability to share our strengths with the whole.

When this value is maintained and the service is delivered in a balanced way, little conflict or constraint is placed upon the front line worker. However, when expectations supersede capacity to give, there is a high risk of creating an imbalance in the worker, affecting not only their health, but also that of the social/ helping system.

\section{Community and Personal Expectations}

It is critical that we assess the expectations that we place on our front line workers to determine how realistic these are. Too often, workers are on call $24 / 7$ with little to no reprieve. Despite this reality, Aboriginal frontline workers are expected to continuously respond to crisis after crisis, and are often criticized for not responding fast or well enough. By maintaining such unrealistic expectations of our workers, are we not dehumanizing their capacity to be effective in their work, and by so doing, limiting our health and social systems?

A huge proportion of helpers that we have come to know have a personal vested interest in their chosen profession. Many individuals who participated in our workshops have shared that they sought careers in the helping profession due to their own desire to help or change their personal, family situation and community.

We get caught in our need to be needed, commonly as community workers, we can easily take on a rescuer identity, trying to rescue individuals, their families and the community. This can often lead to confusion regarding the limitations of our roles, or the development of an unrealistic expectation.

Magical thinking and believing that an outside source has the power to rescue is an impact of colonization, it is a method of surviving oppression. Mullaly (2002) identified key methods in which oppressed populations survive and respond to oppression at a personal level and magical thinking is one method in which we have commonly encountered. Following are a couple of examples in how this way of responding transforms in our community.

Participants shared these stories during the course of our workshops:
This is very true for my case, as I became involved in the helping profession because I was passionately committed to breaking the cycle of abuse in my family. When I got the job as family violence coordinator, I threw myself wholeheartedly into the position; it became my life. I believed I would stop the family violence in my community. The first time I got a notion of the magical thinking and the huge expectations placed on the position was when I was summoned to the Chief and council office. The Chief and council 
members were demanding that I intervene in a dispute occurring between two armed men who were fighting over a dog. I knew both men I grew up with them. There was no police, everyone was fearful of these men. Somebody had to do something (personal communication, December 2004).

I was new in recovery, I felt so passionate about my healing journey. I was enthusiastic to share my newfound knowledge about living straight. I also wanted to give back, I carried guilt about all the wrongdoings I did during my drinking days. When the posting for drug and alcohol counselor came up I put my name in and I got the job never expecting to actually get it. Before long I was racking in the overtime, I was asked to be on this committee and that committee. Next thing I knew I was spinning too much too soon. I quickly became cynical and I fell back into that stinky thinking (TP Personal communication April 2008).

These examples bring to surface the reciprocity effect of expectations; what we believe to be our role also feeds into what the community membership believes is our role. If we take on the role of rescuer or caped crusader then those around will gladly pass the duties and responsibilities over to the rescuer. As the identified professional within the community, the frontline worker quickly becomes inundated with responsibilities and an overbooked workload.

This is compounded by the likelihood that the worker who takes on the rescuer identity or the role of the caped crusader is susceptible to overload because of an inability to say no.

This inability takes root in a place of internal shame and guilt; the internal messages often are, "I am just supposed to be strong all the time. I don't want anyone to worry about me. Seeking help would make me look weak." Within a very short period of time, the worker begins to feel resentment and develop a cynical view about their work and/or coworkers; and such begins the process of burnout.

The flip side of this dynamic is that those who surround the worker (coworker, community members, policy makers) easily feed into this dynamic, setting unrealistic demands upon the individual and falling prey to the hands of the rescuer. They too develop a mode of magical thinking. In the above story, the leadership of the community is making unrealistic demands upon the worker, feeding into magical thinking and promoting the belief that the worker has the skill and competency set to de-escalate an armed conflict. The worker, in this situation, who is set on rescuing, will put his/herself in harms way.

Another dimension of unrealistic expectations that has surfaced repeatedly in our workshops is the notion that workers are expected to be perfect, flawless, and problemless. For example, let us refer to the story of a woman who worked as a CHR in her community.



The CHR became the target of gossip and ridicule, and consequently it affected the efficiency of her interventions.

Thinking that Aboriginal workers are immune to the social malaise plaguing our communities dehumanizes the worker as well as their family members. Antone (1986) identified ethno stress as a consequence of influences from the colonizers, part of which is a dehumanization process. The dehumanization process in combination with magical thinking and believing in a supernatural force to solve the problem, we set the unrealistic expectation that Aboriginal workers and their family members do not experience social problems and interpersonal difficulties. In cases like the CHR, the problem is compounded by the reality that the worker is limited in who and where they can turn to for help and support. This becomes very isolating for the worker and the family. A key practice to ensure health and balance is to be part of a strong social network.

An aspect that is also critical in the expectation levels of our workers, is that of history. The history of the position one occupies the personal history of individuals; each one of us has a story. It could be a story of abuse, a sordid past linked to crime, the struggle for sobriety, the healing story surviving residential school. Family history and community history also impact on the expectation scale. Having a solid understanding and acceptance of where we come from helps counter the negative energy directed towards us.

In order to decrease the stress levels of our frontline workers a reasonable level of expectation could clearly be defined to match the needs of the position. This would greatly increase the potential of the effectiveness of our frontline workers while also minimizing the turnover rate; perhaps policy makers and community members need frequent reminders of the level of responsibilities workers hold in their positions. 


\section{Knowing - The Privilege of Holding Information}

It is heavy knowing and understanding, perhaps there is some wisdom in the saying, and Ignorance is bliss (MG, personal communication, 2001).

Once we have earned the trust as a worker in the community, we get to know the most intimate details or secrets of our fellow community members' lives. When a person discloses a secret, a pain or an abuse, it is a privilege and very sacred information. As workers, we then become the container for holding that information, and it is our moral and professional duty to guard the confidentiality in which it was disclosed.

While it is a privilege to earn trust and hold the information, it can also become a burden, especially when, "knowing" gets real close to our family dynamics.
As the family support worker, I was called into support a family that had discovered that their 10 year old son was a victim of sexual abuse. An intervention occurred because this young boy was acting out sexually with children in the lower grades. My niece and nephew, who attended the same school, were in the lower grades and had been affected by this young boy. The evening following the intervention, our family had a dinner get together and the subject of this family came up, and gossip being gossip, many theories went around. I sat silently, listening, growing more and more uncomfortable. Then a family member said, "You work in the services. What do you know?" I reminded them that I had taken an oath of confidentiality and that I would remain true to that oath. I find it so hard sometimes to not comment. I am constantly conscious of what I know and how I know, from where I know (SG, personal communication, 2000).

Furthermore when the secrets of adults who have been abused sexually in childhood begin to surface, we become the captor of those secrets, which forever changes our perception of community members identified in the disclosure. One particular person I worked with affected my perception of a fellow community member. The following examples illustrate the delicate position we may find ourselves in:

E kept the secret of abuse until he was 40 . He started seeing me and slowly began sharing the sordid details of his childhood. His grandmother, a powerful woman in the community, had sexually abused him over a two-year period from age 11-13; his sexuality and relationships scarred for his lifetime. I knew the woman and once I knew E's story I could never look at the woman the same. E had no desire to seek a criminal penalty, he just wanted healing; he didn't want to implicate the justice system and besides he said, 'She is an old woman now' (EPN, personal communication, 2007).
Even the most altruist, compassionate and empathetic person will become affected by "knowing," working and living with individuals seeking our help. Ultimately, it changes who we are. These examples raise the concept of overlapping relationships and role conflict. As people who live, sleep, play and work with our own people we have multiple roles. As worker we are confronted daily with the ethical dilemma of role conflict and overlapping relationships. A literature review by the Canadian Social Work Association stated that role conflict is an example of working conditions that negatively impact the workers well being (2004). A strategy to maintain the professional boundary is to name the conflict. That requires that we as professionals develop and plan our support system even when in our community we do not receive the clinical supervision necessary.

\section{Knowing your own darkness is the best method for dealing with the darkness of other people (Carl Gustav Jung).}

The other dynamic of knowing, is the need to know one's limitations, your "Achilles' heel" and triggers. The stories heard by workers are often heavily loaded with emotions, which often touch our heart at the very core. Knowing our own triggers as workers is a critical tool. A trigger is something that sets off a memory transporting us back to an event or an original trauma. A flashback can take the form of pictures, sounds, smells, body sensations, feelings, or numbness (Serani, 2009).

In regards to personal history, any situation that resembles a past trauma can inevitably bring to surface any issues pertaining to unresolved emotional or spiritual pain one may still harbour. Each time something comes up as a result of the work, it is important to recognize that there are layers upon layers of self that become masked by victimization and surviving trauma. It is important to become hyper-vigilant in our helping role, and when one is triggered by a client or a situation. We do not have the ability to resolve or deal with the trigger in the moment. It is appropriate to take a moment to acknowledge the emotional drain, and put it in the parking lot. Once the intervention is completed; the person or family in our presence have been helped, then seek out your support network to help process the triggered issue. Therefore it is critical to recognize the trigger. An elder once said, a trigger is a gift to your own growth. Unfortunately not all communities have such networks readily available to their workers.

There are various situations in which we as workers must face the dilemma of role conflict. Both of us have confronted these issues. A very complex example of role conflict surfaces when knowing the offender's identity conflicts with a personal relationship with the offender or his/her family. In many cases, it may be a relative, a friend, and a friend of a friend, an acquaintance or in 
some cases, the identity of your own offender that is being revealed.

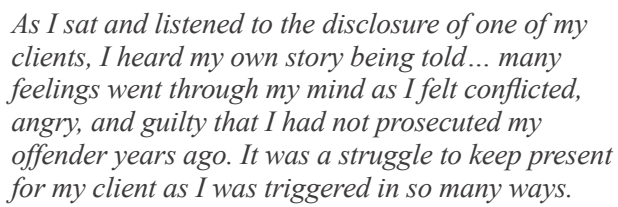

As I sat and listened to the disclosure of one of my clients, I heard my own story being told... many feelings went through my mind as I felt conflicted, angry, and guilty that I had not prosecuted my offender years ago. It was a struggle to keep present for my client as I was triggered in so many ways.

In this case, having processed your own trauma is only half the battle. As workers experience the current trauma they are listening to, they are also experiencing the recount of the event. They are experiencing vicarious trauma, something we will look at more closely in another section. What is essential for survival of the worker, is having access to support, someone with whom they can talk to right away who will not judge their past behaviour.

It is also important for a worker to understand that when a situation is too conflicted for them to deal with, it is in the best interest of the client that they to step away. A strong supervisor will be able to guide the worker through these decisions and support them through such a dilemma of role conflict. In the ideal situation, there will be choices. However, in many of our communities, there are few workers, and at times there is but one worker. Thus we carry the privilege and challenge of remaining mindful of the power we possess in knowing and not to exploit the inherent responsibility designated to us in our professional role as worker.

\section{Loyalty and Duty}

It is an inevitable reality that as helpers or leaders, we confront the dilemma of juggling our family loyalty and our professional duty. There are times when our loyalty becomes tied up in unresolved trauma and history. If we do not bring this to our sphere of awareness, it is at this time that we can find our selves in an ethical constraint or we possibly create further trauma to the community system.

According to Family Systems theories, there are rules and norms that abusive families develop. Calof (1988) has identified a number of family proscriptions and injunctions. Family systems of denial create certain unconscious rules, family messages, and internalizations of scripts of behaviour for victims that are virtually universal. Without benefit of recovery, adult survivors tend to function more or less according to these same rules in adulthood. One of the rules is to be loyal. In order to do so:

1. You must protect the family.

2. Keep the secrets.

3. Obey.

4. You must not fight back, disagree or get angry.
I am reminded of the time when as a director of a healing program, I was approached for help by a community member who was in opposition to the present political leadership who happened to be my brother. When this person approached me, it was absolutely clear that my first priority was loyalty to my family. As this particular person in the past had been very hostile and aggressive towards my family members, I knew that my judgment would be clouded by the past. I decided to take a risk and speak the truth without blame or judgment, and I told this person up front that my opinion was shadowed, and that I could not represent or speak objectively on his behalf. While he was very frustrated that he could not receive the service he was seeking, he greatly respected my honesty and the sincerity in my response to him. I recognized that he was triggering emotional issues in me. I acknowledged my loyalty to my family and in being upfront and authentic I remained true in my professional duty.

While this example touches upon the dilemma associated with loyalty it also brings forth the challenges of lateral violence that plagues our communities.

\section{Lateral Violence}

Lateral violence is a manifestation of the worst bad medicine in our community as it chews away at our pride and self worth. High on the list of stressors among Aboriginal helpers is the manifestation of lateral violence, which is killing the spirit of our families and communities.

Jane Middelton-Moz (1999) coined the term lateral violence, which describes the internalization of oppression that leaves us in a state of shame. The shame is a sense of never being good enough, that there is something wrong with our being. Consequently, for anyone to feel a sense of worth, one has to perceive themselves as better than another. The logical defense against this pain is to put others down; by making them look worse than we do.

Furthermore, as in the nature of oppression pointed out in Mullaly (2002), "Oppression is generally understood as the domination of subordinate groups in society by a powerful (politically, economically, socially and culturally) group" (p.27).

There is an enormous amount of research documented that sheds light on the nature of oppression; however for this article we do not explore it in depth but raise it as a crucial influence to take into account.

Lateral violence clearly explains the high level of infighting within our communities, and why it is so difficult for us to trust that another person is genuinely willing to help us. In the course of our work we have put together the following diagram as a visual to explain the concept: 


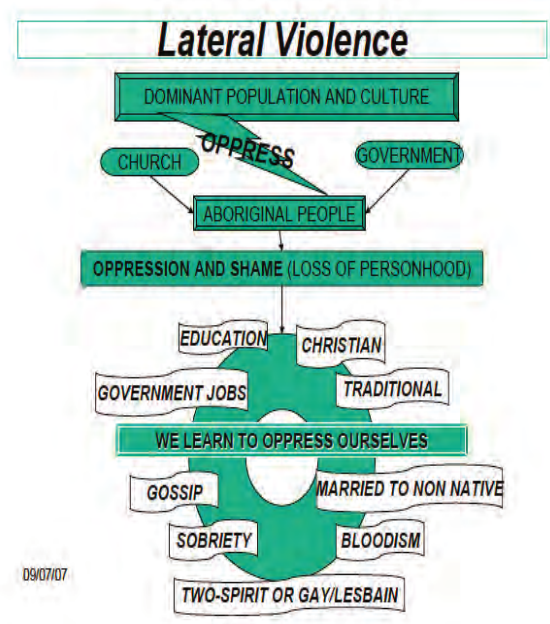

(Goodleaf, 2007)

A huge obstacle for workers working within their communities is the lateral violence that is directed towards identified helpers. It is extremely difficult work to share the pain and struggles of others in the best of times. However, when the situation becomes difficult for the clients, they begin to feel more vulnerable, in turn, they begin to question the motives of the workers, and they may begin to perceive their helper as more of a threat. The client then verbally or physically attacks the worker in an attempt to put them down.

"Who do you think you are? Are you trying to tell me what to do? " said one client of a social worker in her own community. It didn't matter to the client that this was a highly qualified social worker who was genuinely trying to help her with her parenting skills; all she could hear was that "she was not good enough."

Though it would seem to be an advantage to have a member of one's own community as a counsellor, at times it can make looking at oneself more frightening. The need to keep the image of a "good" person or family is very high. What has been lost through this generational oppression by the church and government is the genuine sense of community, of the circle. Historically, our people valued diversity; differences between people were seen not as deficits, but rather as valuable additions to the strength of the whole community. Similarly, it was not shameful to require help, it was expected that everyone needed help at some time. Then when you were functioning better, you would help others.

Today, trust is an ever-present issue and the power differential is an extremely fragile element. In one situation, you may be seen as a helper and thanked, but in another, you may be perceived as the "right arm of the government" that is doing this to get them and put them down. It is important to note that although this can be perceived by the outside as a paranoid kind of response, in Aboriginal communities, it can more likely be understood as a complex trauma reaction. It is also important to note that the "Indian agents," who had total control over the lives of Aboriginal community members, were only removed from their positions on the reserves in the late 1950's. The wounds are still quite fresh.

As workers within our own community, we must try to remember to not personalize the judgments of others. It is equally important that, as workers, we not engage in the power struggle. We must keep in mind that we are also affected by the lateral violence, and that we must not use our power positions in unhealthy ways.

Lateral violence contributes to the present day trauma occurring across Aboriginal territory. While our people are in the process of revitalization the path is still covered by obstacles, the consequences of intergenerational trauma are ever present. Maintaining balance demands that we become more aware of the impacts of lateral violence, intergenerational trauma and more importantly the impact of vicarious trauma.

\section{Vicarious Trauma}

Over the course of delivering our workshops we have encountered individuals who were paying the high cost for empathizing with another's pain, afflicted with vicarious trauma. It is our belief that vicarious trauma is the high cost of caring for and empathizing with another person's traumatic experience over a long period of time. When undiagnosed, the worker is often left feeling confused, full of self-doubt and afraid.

The mainstream literature over the last thirty years has assigned various terms to this trauma. In 1995, the term compassion fatigue was proposed to better described the "cost of caring" that counselors paid (Figley, 1995).

A resource that provides valuable insight into the understanding of vicarious trauma is the Guidebook on Vicarious Trauma: Recommended Solutions for Anti-Violence Workers (2001). This guide provides the definitions that describe the profound effect on therapists resulting from exposure to the trauma experiences of their clients. These are offered by those in the vanguard of this emerging field of study such as Pearlman, Saakvitne, MacIan (1995) and the rest of the team from the Traumatic Stress Institute Center for Adult \& Adolescent Psychotherapy. All provide valuable insight into vicarious trauma.

Compassion fatigue, vicarious traumatization, secondary traumatization, secondary stress disorder, insidious trauma and vicarious trauma are all terms that 
are used in an attempt to label and define what happens, why it happens, and how to live healthily with the experiences (Richardson, 2001).

Providing a theoretical framework to understand vicarious trauma is validating and to move forward we need to be accepting of the deep changes that occur in workers as a result of working with the levels of trauma that frontline must face. When someone hears stories of trauma on a regular basis, it begins to affect the way in which they see and relate to the world.

Over and over again those individuals on the frontline shared with us how their perceptions of the world began to change. The following are clear examples of how vicarious trauma affects the way in which we see and relate to the world.

\begin{abstract}
I worked with troubled youth so often that I was surprised and skeptical when I was with a youth who said she was genuinely happy. I thought that to be peculiar or abnormal and more importantly, that she must be making it up. After spending a little time with this youth, I realized she really was happy and had a good family and good support. I also realized I had become jaded and that I may need a break from my work ( $Y W$, personal communication, 2009).
\end{abstract}

I wouldn't let my children go to their friend's house for fear that someone would abuse Them (YPSW, personal communication, 2008).

I could not trust anyone. I isolated myself in my home and I stopped asking people for help (CHR, personal communication, 2008).

Researchers Pearlmann and Saakvitne (1995) believe that when we listen to the traumatic stories shared by clients, our view of the world and ourselves is permanently transformed. The effects of vicarious trauma are cumulative and permanent. That is to say it gets harder to manage the effects of the stories the longer one works in this field.

\section{I started seeing everyone as a potential sex offender, I would "freak-out" if any adult tried to talk to my kids... I started isolating my family and myself. I was always angry (SOC, personal communication, 2008).}

In my experience as a clinical psychologist in Aboriginal communities over the past 20 years, I have heard many horrific stories and have sat with many workers, healers, ministers and family members who have offered to help to hold another's pain. In many cases, these same helpers began experiencing much of the following symptoms: a feeling of hopelessness, a loss of compassion, depression, numbness, inability to contain intense emotion, pervasive sense of anxiety, vulnerability, nightmares, intrusive thoughts, fear for self and family, a weakened sense of safety, becoming very suspicious of others, a diminished belief in the human race, alienation, "You'll get hurt if you trust," flashbacks, an attitude of apathy where you believe that nothing will help because the world is no longer safe. These symptoms have been identified as those corresponding to the definition of vicarious trauma or compassion fatigue.

Although all workers in the helping field are susceptible to vicarious trauma, there is an added component when we are dealing with Aboriginal people who work within their own communities. The extra burden lies in the reality that the trauma that they may be experiencing vicariously, they may also be experiencing directly. That is to say, when some clients tell me their story of trauma, I may have also experienced the same trauma. For example, when one of my clients told their story of the accidental death of a child in the community, I was also experiencing the loss related to that child. At times, I, as the therapist, may not have had the opportunity to debrief my experiences; yet I would be expected to assist another in processing their losses.

There are instances where police officers are called on to arrest one of their relatives, or talk to a family member who is suicidal. This intervention can be quite traumatic for the worker, and many times these same workers are asked to help to process or debrief others after the incident. The worker's needs and feelings are often ignored for a variety of reasons that have already been outlined, so the task of keeping things straight is a juggling act for most Aboriginal workers.

When many factors influence each other, it creates stress for the individual worker. As Aboriginal people, we are part of a circle - the circle of creation, which includes Mother Earth, the community, the family and the individual. We cannot remain separate, since doing so goes against our teachings. Yet separation is part of how the non-Aboriginal services system operates. As well, the personal is very separate from the professional; for our frontline that is a luxury we do not have, the personal and professional are intertwined. If we are well, then we can help those who are not well. The idea that we may be healing ourselves as we are helping others is not really within the theoretical frame of the "professional" in a hierarchical system.

When we are expected to know the answers, we are put into a very difficult position. Consequently, the burden is quite heavy and the lines difficult to unravel. The need for boundaries is an essential tool, yet it can also become our crutch. If, in fact, we could see that we are all trying to figure things out together, then we would not have to carry such a burden, our experience is one parallel experiences. This, however, would also take its toll on our perceived role as helpers or our esteem in having the 
ability to help.

The dynamic of vicarious trauma also ties into the stress factors of an individual working in the helping/ security/medical profession. According to social worker Deborah Sinclair (2006) there are three factors of stress that influence workers:

1. There is the individual stress that the person deals with in his or her daily life that includes personal trauma or history as well as individual coping strategies for dealing with and managing stress.

2. There is life stress that includes the present stressors that the individual deals with on a daily basis. This may include family difficulties, addiction of family members or their personal struggles with addictions, etc...

3. Organizational stressors include the expectations that the employer has on the worker and the amount of support that they provide, or in many cases, are unable to provide to the worker. These factors include salary, time off, training, and availability of resources.

In order to adequately address the stressors influencing Aboriginal workers we have added a community stressor:

4. Under the umbrella of community stressors there is the reality of historical trauma, and dynamics of oppression. Additionally there are the present day acts of violence such as vandalism, sexual abuse, murder, gun incidents, accidental deaths, violent crisis, or political or religious struggles.

Based on Sinclair (2006) Diagram 1 illustrates how these stressors in mainstream and the professional boundaries in mainstream maintain a distinct separateness. The realities of personal and professional boundaries of Aboriginal workers do not have the luxury of remaining so clearly separate. The stressors and influences become overlapped. The more the worker is exposed to traumatic events and disclosures, the perception of the world becomes increasingly distorted and the world becomes a dangerous place to live. The reality of the environment becomes overbearing as illustrated in Diagram 2.

As illustrated, it becomes difficult to manage and to separate these factors or roles. Especially when life, individual, and organizational factors are compounded by community factors; one becomes so influenced by the narratives of others' pain and sense of safety. Each part becomes so enmeshed, consequently impacting our perception of life, community and security.

One explanation as to how our frontline becomes so enmeshed may be explained in a study undertaken by Mussell (2005) regarding the healing of First Nation men. Serious discussion of roles and responsibilities

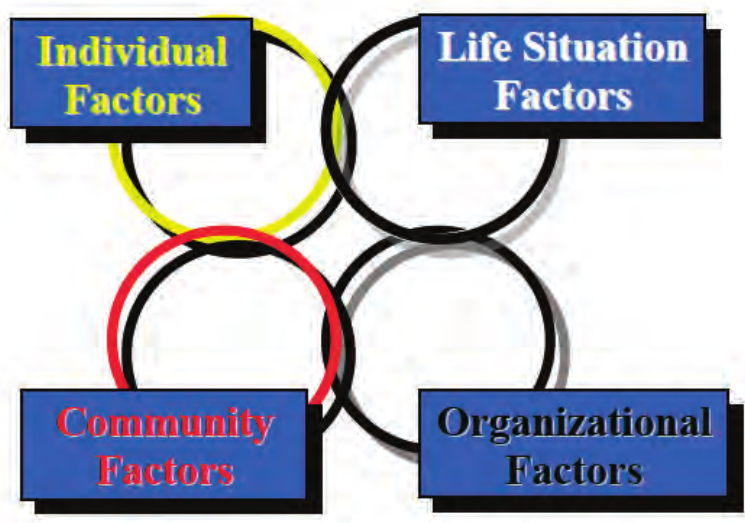

Diagram 1.

(Sinclair, 2006)

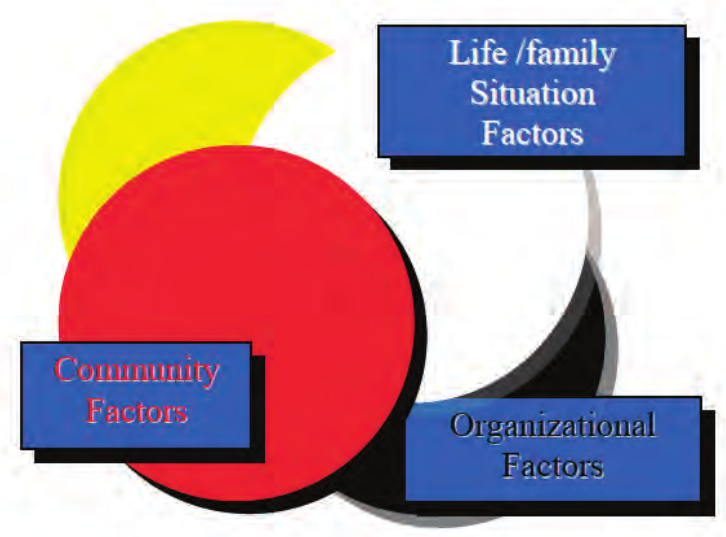

Diagram 2.

(Goodleaf, 2007)

seldom takes place in most communities, for reasons including absence of trust and serious gaps in the teaching and learning that took place at home, in school and in the community. Such discussion is often viewed as threatening because "taking a look" at one's own performance within the family and community is getting too personal. Add to that the mistrust created as a result of lateral violence and the environment is set up to sabotage a system of frontline workers.

\section{Balancing the Influences}

As a part of our wellness plan we attempt to reframe the impact of these factors and how they influence our lives. The first goal is to identify and name them, to bring each aspect to our conscious mind and to 
understand how each component evolves in our day to day activities. As part of our workshop curriculum we placed each component in the setting of the Medicine Wheel. The Medicine Wheel is a tool that has many layers that remind us of our interconnectedness to self, to all elements, beings and spirit (see Diagram 3 below). The wheel provides a graphic that depicts balance and also provides a tool to do self assessment to be aware of where we are in managing the individual/historic, life/family, community and organizational aspects of our lives. The second goal is to take personal ownership and personal power of each component and to implement strategies that guide us to balancing each aspect of our being. In this way we own our healing and lay the foundation for revitalization of our ways. Our frontline flourishes and a culture of care ensures the survival of our communities.

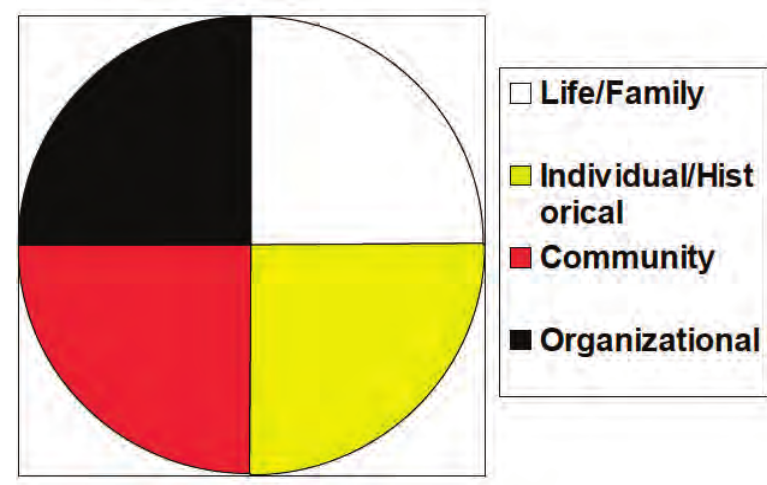

Diagram 3.

(Goodleaf and Gabriel, 2009)

This is really the only way that our communities will survive. We cannot solely take on the role of healers of our community - we can simply take part in awakening the determination of others within our communities to use their own gifts to effect changes. In turn, these changes will begin to transform the nature of the problems in the community. Ownership of the pain, the problems and the specific issues in our communities are the means by which we will all continue to heal together.

Taking ownership means that we are in a parallel process. Through trial and error we have learned that in order to be a helper in Aboriginal territory requires a commitment to our own ongoing healing journey. Thus, we are in a parallel process as helpers, helping our community through decolonization and to change destructive patterns at the same time we are doing our own healing work. To ignore that we need healing is irresponsible as we have all been traumatized by colonization and assimilation and most importantly we are all hit by the lateral violence in our community. To prevent becoming the wounded healer we all have an obligation to define and implement our own wellness plans. As our Elders have stated, healing is a life long journey.

This quote speaks to the concept of refueling our spirit or re-energizing. Spoken by Mother Theresa,

To keep the lamp burning, we have to keep putting
oil in it.

The strategies we believe to be most effective to prevent vicarious trauma are to have the following available for workers:

1. Continuous opportunities for debriefing of emotions.

2. Engage in support groups for caregivers.

3. Involvement in activities of hope.

4. Balancing a case load with other types of professional activities.

5. Respecting our own personal boundaries.

6. Having realistic expectations.

\section{Conclusion}

The experiences and observations we have shared in this article tell the stories of some of the people on the front line of revitalization. It is our hope that this article sheds light on the challenges and strengths of Aboriginal helpers, who in the hardest of situations bring forth dynamic, innovative and creative health, social, justice and healing work - work that is happening in Aboriginal country across Turtle Island. Their stories and truths are testimony to the extraordinary resiliency that is part of our culture's and nation's DNA. Without this resiliency, we would have been assimilated or become extinct.

Our journey as helpers has taught us many lessons about surviving assimilation, human nature, family, community and nation. We are impacted daily by various influences that guide or help us in our choices of responses or actions. In this article, we have sought to identify some of these, such as the: influences, expectations (communal \& personal), the privilege and dilemmas of holding information (knowing), loyalty and duty, lateral violence, and vicarious trauma. Certainly there are other influences that impact upon us; we chose those listed above because they have repeatedly surfaced in the work that we do with Aboriginal helpers.

Wellness strategies and common best practices have been shared throughout the article, in an attempt to shed light on how we, as Aboriginal helpers, can continue to do the work we do, and to continue to be of service with passion. To summarize, here is a list of strategies we apply in our lives: 


\section{The Frontline of Revitalization: Influences Impacting Aboriginal Helpers}

- Recognize when you are caught in the need to be needed;

- Be mindful of role conflict or overlapping relationships, name it;

- Having access to another helper to share situations (clinical supervision);

- Know your limitations, triggers, and/or Achilles' heel;

- Acknowledge that it is okay to make a mistake, and to learn from mistakes;

- Ask questions, especially the hard ones;

- Acknowledge your own pain and deal with it at the appropriate time;

- Take a risk and speak the truth without blame or judgment;

- Distinguish the difference between loyalty and duty;

- Accept that it is okay to ask for help - our culture is one that emphasizes interdependence;

- Commit to your own healing retreat;

- Do not personalize the judgments of others, and;

- Always be conscious of the power you hold as a helper, and use it with people, as opposed to power over people.

Truthfully, it is important for us workers to remember that there are many influences that touch our perceptions and actions daily. When we enter the helping profession, we go in whole-heartedly, and we go in wearing rose coloured glasses. When we gain experience as a helper, our perspective of our community and of the world changes. We have our glasses removed, and begin to see very clearly, sometimes too clearly. We see the darkness, the pain, and on the other side, we also see the results of healing, wherein lies our reward. The prize is the transformation and the healing when the darkness is lifted. The revitalization is nurturing our families in culture, in our ceremony, in our dances, our songs and our ways of healing.

There is still much work to do in our communities and Nation to revitalize our Aboriginal identity, our culture and our world. The healing of our communities will be stronger and greater if we apply our traditional values. To return to our values we need to return to a culture of care. "Culture of care - is vital for successful performance and has five dimensions: mutual trust, active empathy, access to help, lenience in judgment and courage" (as cited in Mussell, 2005, pg. 7).

We need to continue to nurture the fields of work that engage our helpers. We need to inspire the next generation of helpers to take up where we have left off. We need to incorporate a culture of caring to solidify the support systems for our front line workers, and show that care for caregivers - that helping the helpers, is a priority in our community wellness planning.

Nià:wen....

\section{Bios}

The authors are both Kanieke'ha:ke professionals.

Suzy Goodleaf is a licensed psychologist from the community of Kahnawake. She has worked in private and public practice for over 20 years, as a child welfare worker, a researcher, a facilitator, clinical supervisor, and a consultant.

Wanda Gabriel is presently employed as a social worker for the Cree Nation in Northern construction camps. She has also worked in private and public practice for over 20 years, during which she serviced her own community of Kanehsatake as coordinator, facilitator, and director. She has also worked in child welfare, in urban programming, as an instructor, researcher and clinical supervisor. 


\section{First Peoples Child \& Family Review, Volume 4, Number 2, 2009}

\section{References}

Antone, R., Miller, D. \& Myers, B. (1986). The power within people: a community organizing perspective. Canada: Tribal Sovereignty Associates.

Calof, David L. (1988). Adult survivors of incest and child abuse, part one: the family inside the adult child. Family Therapy Today, 3(9), 1-5. Van Nuys, CA: P. M. Inc.

Canadian Association of Social Workers, (2004). The Impacts of Working Conditions on Social Workers and Their Practice. A CASW Review of Current Literature, CASW, Ottawa.

Esquimaux-Wesley, C.C., \& Smolewski, M. (2004). Historic trauma and aboriginal healing. Anishnabe printing: Kitigan Zibi.

Figley, C.R. (Ed.). (1995). Compassion fatigue: coping with secondary traumatic stress disorder in those who treat the traumatized. New York: Brunner/Mazel.

Goodleaf, S. (2007). Care for caregivers workshop. Proceedings of CSCL '05: First Nations and Inuit Quebec \& Labrador Suicide Prevention Association Conference. Montreal: Canada.

Jung, Carl, Gustave.(n.d.) Carl Gustave Jung Quotes. Retrieved March16,2009 from http://thinkexist.com/quotation/knowing your_own darkness is the best method for $/ 201427$. $\underline{\mathrm{html}}$.

Mullaly, R. (2002) Challenging oppression; a critical social work approach. Canada: OUP.

Mussell, B. (2005). Warrior-caregivers: understanding the challenges and healing of first nations men. Anishnabe printing: Kitigan Zibi.

Middelton-Moz, J. (1999) Boiling point: the high cost of unhealthy anger to individuals and society. Deerfield, F., USA: HCI Publishers.

Pearlman, L.A., \& Saakvitne, K.W. (1995). Treating therapists with vicarious traumatization and secondary traumatic stress disorders. In C. Figley (Ed.), Compassion fatigue: coping with secondary traumatic stress disorder in those who treat the traumatized (pp. 150-177). New York: Brunner/Mazel. 